Article

\title{
Energy Saving Assessment of Semi-Transparent Photovoltaic Modules Integrated into NZEB
}

\author{
Cristina Cornaro ${ }^{1, *}$, Giulia Basciano ${ }^{1}$, Valerio Adoo Puggioni ${ }^{2}$ and Marco Pierro ${ }^{1,3}$ \\ 1 Department of Enterprise Engineering, University of Rome 'Tor Vergata', Via del Politecnico, \\ 1, 00133 Rome, Italy; g.basciano@hotmail.it (G.B.); marco.pierro@uniroma2.it (M.P.) \\ 2 EnUp srl, Via dei Monti di Primavalle, 151, 00168 Rome, Italy; puggioni@enup.it \\ 3 Institute for Renewable Energy, EURAC Research, 39100 Bolzano, Italy \\ * Correspondence: cornaro@uniroma2.it; Tel.: +39-06-7259-7233
}

Academic Editor: Cinzia Buratti

Received: 7 December 2016; Accepted: 18 January 2017; Published: 24 January 2017

\begin{abstract}
Photovoltaic semi-transparent materials (STPV) integrated into glazing systems can offer good potential for energy saving to buildings, influencing heating loads, cooling loads, and lighting, as well as electricity production. Moreover, with the new stringent regulations issued by various European countries, following the Energy Performance of Buildings Directive (EPBD, 2010/31/EC), the building envelope, including the glazing elements, needs to have high thermal performance to guarantee Nearly Zero Energy Building (NZEB) behavior. This work presents an assessment of energy saving potential of 4 different types of STPV with respect to conventional double pane glass. Dye sensitized solar modules (DSM) and thin film modules were considered in the study. Simulations based on an IEA reference office building (STD) and on reference buildings prescribed by the new Italian building energy performance regulation (NZEB) were carried out. All the glazing peculiarities could be simulated using only one simulation tool, namely IDA ICE 4.7.1. Dye sensitized solar modules resulted as the best performing devices for all orientations and climate zones. The work also evidenced how the requirements of NZEB seem to be too stringent for insulation properties, especially for the climate zone of Rome.
\end{abstract}

Keywords: energy saving; buildings; NZEB; photovoltaic; thin film; BIPV; DSC; dynamic building simulation; IDA ICE

\section{Introduction}

Glazing systems are the most fascinating but also the most critical elements of the building envelope. If, on one side, they can inspire new architectural forms and provide visual comfort to the occupants, on the other side, they are the major source of heating load during summertime and thermal losses during winter, reducing thermal comfort and increasing heating and cooling demand. Therefore, aesthetic and functionality are two aspects that need to be balanced to obtain a product that is compliant with the more recent and strict requirements provided by the energy performance directives at European [1,2] and National [3] levels. In particular, Italy, following the European directives on the energy performance of buildings, recently issued a norm that prescribes the minimum thermal requirements for new buildings and existing refurbished buildings to be considered as NZEB [3]. The norm requires the comparison of refurbished or new building energy performance with the performance of a reference building with the prescribed minimum thermal requirements.

Recently great attention has been devoted to the study of new high performing materials for glazing systems, confirmed by three extensive reviews on the latest developments on glazing technologies published in the literature in 2015 and 2016 [4-6]. Among the emerging systems, photovoltaic semi-transparent materials (STPV), integrated into windows as active elements, seem to 
be very promising and are starting to be studied more extensively at theoretical and experimental levels. Cae et al. [7] evaluated the performance of three different amorphous silicon cells when integrated into windows. They built their own cells in the lab, and they were able to fully characterize the devices from the optical, thermal, and electrical points of view. These data were used as the input for an Energy Plus model of a typical office building located in six different climatic zones in US. They concluded that at low and mid latitudes, STPV can produce a 30\% annual energy saving while, for cities like Chicago and Duluth, these systems did not provide a real gain. For what concerns the Mediterranean area, Olivieri et al. performed a couple of studies to characterize the energy performance of glazing elements with amorphous silicon located in the city of Madrid. They set up an experimental system that allowed different kinds of amorphous silicon semi-transparent glasses to be thermally, optically, and electrically characterized [8]. They also evaluated the energy saving potential of STPV elements located in Madrid with different gradations of transparency, comparing the results with the energy performance of a standard glazing system [9].

Liao et al. carried on a study using Energy Plus to evaluate the energy performance of STPV using amorphous silicon with different characteristics. Their results demonstrated that a-Si PV glazing holds great potential in terms of energy performance under the climate conditions of Central China [10]. Among the STPV, organic photovoltaic devices have a great potential for integration into windows; in particular, Dye Sensitized Solar Modules (DSM) are the most promising devices for this purpose, since they are built on glass substrates [11,12]. Recently some works appeared in the literature [13-17] regarding the evaluation of the thermal, optical, and electrical characteristics of these devices; however most of them are focused on solar cells of small dimensions that usually have better performance than modules, which are the real devices to be integrated. These data have been used as the input for models that provide energy assessment and potentiality of energy saving for buildings equipped with these devices and subjected to different configurations and different climates. For example, Yoon et al. [18] built and characterized their own dye solar cells (DSC), varying the thickness of the active material, and used their results as the input to a simulation program in which DSC windows were integrated into office buildings in Korea. They found that lowering the transparency of the active material produced low energy consumption in winter, mainly due to the PV energy production. This improvement depends on the cell efficiency; at low efficiency levels, the energy consumption is almost constant with the transparency, while if the efficiency could double with respect to the actual values, a certain dependence of consumption on transparency appeared. Lee et al. [19] evaluated the potential energy saving capacity of DSC integrated in a reference building in six different climatic zones in the world. They chose Miami, Seoul, Sydney, New York, Berlin, San Paolo, and Moscow as 7 cities representative of the 6 zones. They tested six different DSCs, taking their characteristics from a national database. It appears that the efficiencies considered here are not very representative of the realistic efficiencies found for DSM that could be really integrated in a glazing system. They evaluated the 4 DSC performance with respect to 4 window to wall ratios, 4 orientations, and 7 cities. They concluded that, while in Berlin and Moscow the advantage is low, a percentage variable between $12 \%$ and $22 \%$ of energy saving due to PV production is reached for the other cities. Reale et al. [20] developed a model of DSM using data coming from outdoor conditions, and they used it to estimate the producible energy of a DSM with respect to the well-established technologies for a generic STPV installation. They concluded that DSMs should have an equivalent efficiency in real outdoor conditions $16 \%$ higher than the one at standard test conditions in the laboratory $(\eta=3.36 \%)$.

An attempt has been made to resume the most significant results found in the literature for STPV testing in terms of energy consumption, considering different technologies and locations. Table 1 is the product of this effort. However it has to be considered that these studies were carried on with different hypothesis on the model construction and evaluation so that a direct comparison among the results and with the results obtained in this work is difficult and not realistic. 
Table 1. List of the major results obtained by various authors in the literature in terms of energy consumption, varying the location and the photovoltaic technology on the windows.

\begin{tabular}{|c|c|c|c|}
\hline Authors & Cities/Country & Technology & $\begin{array}{l}\text { Lower Annual Energy Consumption } \\
\text { with Respect to RG (\%) \& }\end{array}$ \\
\hline Chae Y. T. et al. [7] & $\begin{array}{c}\text { Miami (MAI) } \\
\text { Phoenix (PHX) } \\
\text { Los Angeles (LAX) } \\
\text { Baltimore (BAL) } \\
\text { Chicago (CHI) } \\
\text { Duluth (DUL) }\end{array}$ & $\begin{array}{c}\text { Double glazing; a-Si PV1; a-Si } \\
\text { PV2; a-Si PV3 * }\end{array}$ & $\begin{array}{l}\text { (MAI) }-22.2 \% \text { with a-Si PV3 } \\
\text { (PHX) }-23.4 \% \text { with a-Si PV2 } \\
\text { (LAX) }-38.5 \% \text { with a-Si PV2 } \\
\text { (BAL) }-13.2 \% \text { with a-Si PV1 } \\
\text { (CHI) }-0.53 \% \text { with a-Si PV1 } \\
\text { (DUL) }+26.6 \% \text { with a-Si PV1 }\end{array}$ \\
\hline Olivieri L. et al. [9] & Madrid (MAD) & $\begin{array}{l}\text { Double glazing; a-Si 0; a-Si 10; } \\
\quad \text { a-Si 20; a-Si 30; a-Si } 40^{\#}\end{array}$ & (MAD) $-16.7 \%$ with a-Si 20/30 \\
\hline Liao W. et al. [10] & Central China & $\begin{array}{c}\text { Double glazing; a-Si PV low; } \\
\text { a-Si PV high }\end{array}$ & $\begin{array}{l}\text { Case } 1:+0.65 \% \text { with a-Si PV low } \\
\text { Case } 2:-17.7 \% \text { with a-Si PV low } \\
\text { Case } 3 * *:-29.1 \% \text { with a-Si PV low }\end{array}$ \\
\hline Yoon S. et al. [18] & $\begin{array}{l}\text { Sangsachang-dong, } \\
\text { Hanam-si, Gyeonggi-do, } \\
\text { South Korea }\end{array}$ & $\begin{array}{c}\text { RG and DSCs with } \\
\text { transmittance from } 60 \% \text { to } 10 \%\end{array}$ & $-7.3 \%$ with DSC Transmittance $10 \%$ \\
\hline
\end{tabular}

* PV1, PV2, PV3 = different kinds of transparency of amorphous silicon (a-Si); \# 10, 20, 30, 40 = different transparencies; low, high = transmittance; ${ }^{\&} \mathrm{RG}=$ Reference Glass; no PV generation considered, negative value means saving; ${ }^{* *}$ each case varies geometry of room and window tested.

Despite the recent attempts, as yet few works regard the evaluation of thermal and electrical properties of DSM for STPV, especially in real operating conditions [20,21], so that few realistic input data are available to evaluate the reliable potential of energy saving in buildings.

Moreover, to the authors' knowledge, such investigations have not yet been made for the Italian area with specific reference to the recent norms.

The objective of this work is to investigate the energy saving potential of four different kinds of STPV with realistic thermal and electrical characteristics. Two thin films of PV glazing systems and two DSMs integrated into windows have been tested. In particular, for DSMs, thermal and electrical characteristics have also been directly measured in real operating conditions. The study is focused on office buildings located in a Mediterranean climate region (Italy). The study can help engineers and architects in the choice of active glazing systems as effective means for energy saving, particularly with respect to the reference introduced by the new Italian norm [3].

\section{Methodology}

An integrated simulation approach has been used in this work. Thermal, electrical, and daylighting perspectives have been explored using only one simulation tool, IDA ICE 4.7.1 by EQUA Simulation [22]. The investigation has been organized in two sequential steps named Phase A and Phase B, as shown in Figure 1.

Phase $\mathrm{A}$ is focused on the evaluation of the best performing glazing system for different building orientations and at different locations in the Italian peninsula. For this purpose an office room reference model has been built in the simulation environment. External wall and window thermal properties represent the average values commonly adopted in the Italian area [23]. The method consists of the following steps:

- $\quad$ three locations representative of North, Central, and South Italy (Trento, Rome, and Palermo) are considered;

- a model of an office building, named STD, is built and validated using data gathered from the literature;

- $\quad$ STD is equipped with two different glazing systems: RG, a typical glazing system taken as reference, and STPV, which represents the various photovoltaic thin film technologies chosen for the study; 
- $\quad$ the annual energy performance of RG and STPV are compared for each location at different orientations of the building (North, South, East, and West).

- $\quad$ for each location, the best choice of STPV is evaluated at the four orientations.

The objective of Phase B is to evaluate the effective annual energy saving produced by the best STPV solutions tested in Phase A, both with respect to the actual average performance of an office building and with respect to the NZEB limits introduced by the new Italian regulation and listed in the following section (Table 4).

The method consists in the following steps:

- $\quad$ the same three locations considered in Phase A are studied;

- $\quad$ two reference buildings are considered: STD, used in Phase A, and NZEB, for which the thermal properties are upper limits for new and existing buildings to be considered as NZEB in Italy. In this case the NZEB building is different for each location;

- $\quad$ both reference buildings are equipped with RG and the best choice (BEST in Figure 1), found in Phase A;

- $\quad$ an entire floor of the office building is simulated for this purpose. The annual energy performance of RG and BEST are evaluated and compared for STD and NZEB buildings at North/South and East/West orientations.
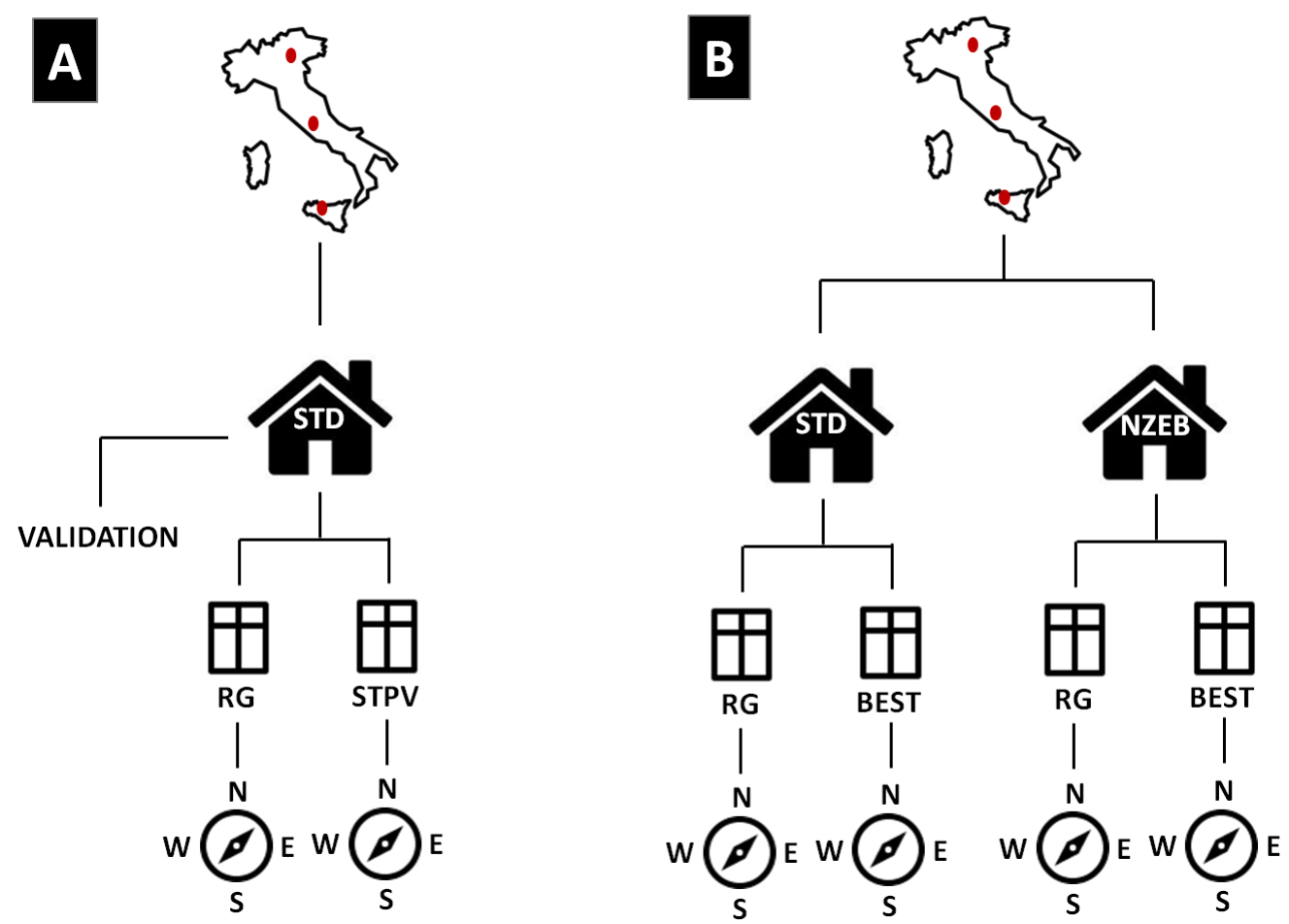

Figure 1. Schematic of the method of investigation used in Phase (A) and Phase (B) of the study.

\section{Climate Conditions at the Three Locations}

According to the Italian norm [3], the cities are grouped into six climate zones depending on their heating and cooling degree days. These zones are classified from letters ' $A$ ' to ' $\mathrm{F}$ ', switching from a hot to a cold climate. The three cities selected for this work are representative of three different zones: Trento (E zone), Rome (D zone), and Palermo (B zone). The Koppen and Geiger climate classification [24] has been used to identify the three cities' climates.

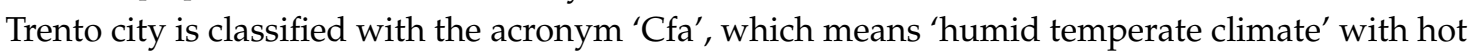
summers (Continental climate) and characterized by an annual rainfall between $700 \mathrm{~mm}$ and $1500 \mathrm{~mm}$. 
The least amount of rainfall occurs in January. The average in this month is $45 \mathrm{~mm}$. The greatest amount of precipitation occurs in November, with an average of $98 \mathrm{~mm}$. Temperatures are highest in July, with an average of $22.9^{\circ} \mathrm{C}$. The lowest temperatures of the year occur in January, with an average of $1.1^{\circ} \mathrm{C}$.

According to Koppen and Geiger, Rome and Palermo belong to the 'Csa' climate. 'Csa' means the temperate and hot climate of the middle latitudes with dry and hot summers and cool rainy winters (Mediterranean climate). The average annual precipitation is around $750 \mathrm{~mm}$.

In Rome, the driest month is July, with $17 \mathrm{~mm}$ of rain. Most precipitation falls in November, with an average of $114 \mathrm{~mm}$. July is the warmest month of the year. The average temperature in July is $24.4^{\circ} \mathrm{C}$. In January, the average temperature is $7.7^{\circ} \mathrm{C}$. It is the lowest average temperature of the whole year.

In Palermo, the driest month is July, with $4 \mathrm{~mm}$ of rain. Most of the precipitation here falls in December, with $90 \mathrm{~mm}$. August is the warmest month of the year. The average temperature in August is $26.2^{\circ} \mathrm{C}$. January is the coldest month, with temperatures averaging $12.1^{\circ} \mathrm{C}$. Table 2 summarizes the main climate features of the three cities.

Table 2. Climate characteristics of the three locations selected for the study.

\begin{tabular}{cccccc}
\hline City & Climate & Annual $\mathbf{T}_{\text {avg }}\left({ }^{\circ} \mathbf{C}\right)$ & Annual $\mathbf{T}_{\min }\left({ }^{\circ} \mathbf{C}\right)$ & Annual $_{\mathbf{T}_{\max }}\left({ }^{\circ} \mathbf{C}\right)$ & Rain $(\mathbf{m m})$ \\
\hline TRENTO & Cfa & 12.5 & 7.5 & 17.6 & 900 \\
ROME & Csa & 15.7 & 10.7 & 20.8 & 798 \\
PALERMO & Csa & 18.4 & 15.2 & 21.7 & 605 \\
\hline
\end{tabular}

\section{Model Description and Validation}

\subsection{Reference Buildings}

\subsubsection{Building Main Features}

The reference building used for this study is a well established model that was originally defined in the European Commission Joule project REVIS and further refined in the International Energy Agency Solar Heating and Cooling (IEA SHC) program Task 27 (performance of solar facade components). The same specifications have been used in the EC project SWIFT and for IEA SHC Task 25 (solar assisted air conditioning of buildings) and Task 31 (daylighting Buildings in the 21st century) [25]. A schematic of one typical floor of the reference building is shown in Figure 2.

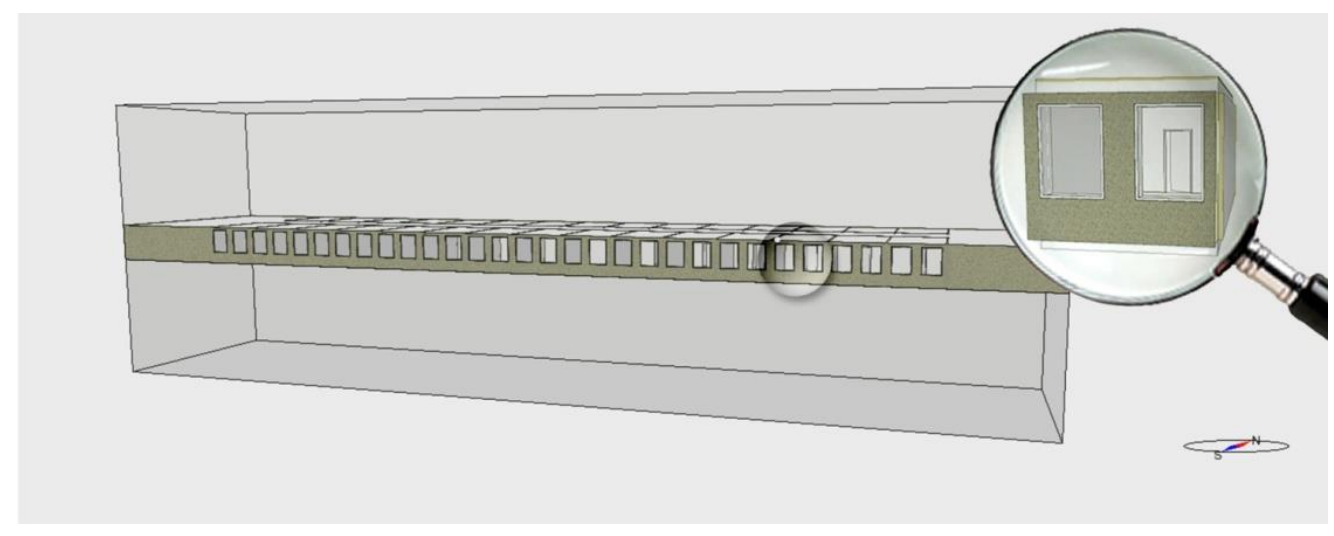

Figure 2. Schematic view of the reference model for an office building.

It is comprised of 210 office modules, distributed over 7 floors and 2 orientations, with 15 office modules per floor at each of the two orientations, separated by a central corridor $3.1 \mathrm{~m}$ wide and 
provided with the staircase/service spaces at both ends of the building. Figure 3 shows the typical plan of a floor. The height of the building is $21 \mathrm{~m}$. The total floor area is $6820 \mathrm{~m}^{2} ; 974 \mathrm{~m}^{2}$ for each floor.

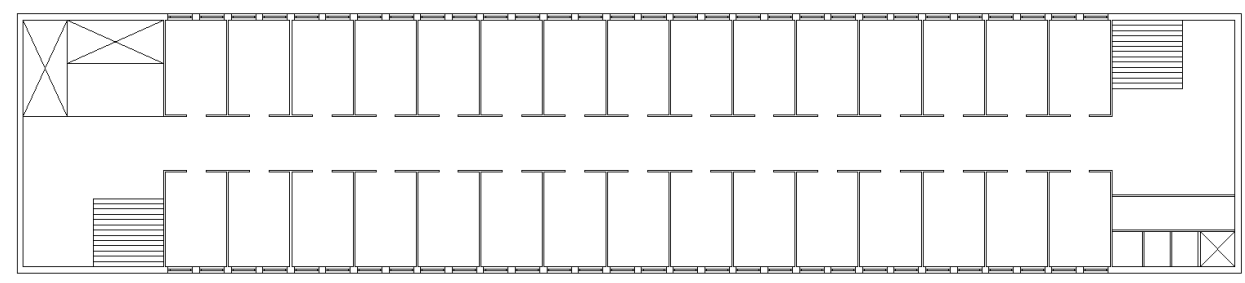

Figure 3. Plan of a typical floor of the office building.

To reduce the calculation time, only one office module (see Figure 2) was considered for the simulations in Phase A. The room is a middle-size office, $3.5 \mathrm{~m}$ in width and $5.4 \mathrm{~m}$ in depth; the height is $2.7 \mathrm{~m}$ and the distance between floors is $3 \mathrm{~m}$.

The office is conditioned by a simple fan coil (nominal power $8000 \mathrm{~W}$ ) coupled to a main plant, one boiler, and one chiller (COP 1.67), which is always on. The fan coil is turned on every work day from 8 a.m. to 7 p.m.

The heating and cooling set point temperatures are maximum $20^{\circ} \mathrm{C}$ and minimum $12{ }^{\circ} \mathrm{C}$ for heating and minimum $26^{\circ} \mathrm{C}$ and maximum $28^{\circ} \mathrm{C}$ for cooling. No air change per hour by infiltration is considered.

The space is illuminated by a lighting system with the target work plane illuminance of $500 \mathrm{~lx}$, according to UNI-EN 12464 [26]. The lighting power density in the office is $8 \mathrm{~W} / \mathrm{m}^{2}$ and the space is occupied by two occupants on weekdays from 8 a.m. to 7 p.m.

For the simulations, the space was assumed as limited by five sides; the internal walls, the floor, and the ceiling were modeled as adiabatic so that only one wall interacts with the outside.

\subsubsection{STD Building}

The standard reference building (STD) represents a typical Italian building. The thermal and optical properties of the building materials were retrieved in [23]. It comes out to an average of the values prescribed in [23] for the different Italian climate zones. The optical and thermal properties of the double glazing RG, taken as reference, and of the wall are showed in Table 3.

Table 3. Thermal and optical proprieties of the double glazing element RG and the wall.

\begin{tabular}{cccccc}
\hline Materials & U-Value $\left(\mathbf{W} / \mathbf{m}^{2} \mathbf{K}\right)$ & Tvis & Tsol & g-Value & $\varepsilon$ \\
\hline RG & 2.783 & 0.461 & 0.382 & 0.473 & 0.83 \\
Wall & 0.66 & - & - & - & - \\
\hline
\end{tabular}

\subsubsection{NZEB Building}

The NZEB building was built referring to the recent Italian norm that fixes the upper limit of the thermal transmittance for opaque/transparent surfaces and g-value for the transparent surfaces according to climate zones by 2019/21. Three cities were selected in this study; Palermo, Rome, and Trento. They represent the B, D, and E climatic zones, respectively. The thermal and optical properties of the transparent materials and opaque walls for the three locations are shown in Table 4. 
Table 4. Thermal and optical properties of the NZEB double glazing element.

\begin{tabular}{ccccccc}
\hline Cities & Materials & U-Value $\left(\mathbf{W} / \mathbf{m}^{2} \mathbf{K}\right)$ & Tvis & Tsol & g-Value & $\varepsilon$ \\
\hline \multirow{2}{*}{ TRENTO } & RG & 1.4 & 0.461 & 0.349 & 0.35 & 0.83 \\
& Wall & 0.26 & - & - & - & - \\
\multirow{2}{*}{ ROME } & RG & 1.8 & 0.461 & 0.349 & 0.35 & 0.83 \\
& Wall & 0.29 & - & - & - & - \\
\multirow{2}{*}{ PALERMO } & RG & 3.0 & 0.461 & 0.349 & 0.35 & 0.83 \\
& Wall & 0.43 & - & - & - & - \\
\hline
\end{tabular}

\subsubsection{PV Glazing Systems}

The simulations were carried out using four semi-transparent photovoltaic glazings and compared to reference glazing previously described. Two STPV using a-Si technology and two elements using DSM were selected for the study. Table 5 lists the properties of the chosen systems. The thermal and optical properties of a-Si were obtained from the laboratory in a previous research study [9]. Each a-Si element corresponds to a specific degree of transparency and their conversion efficiencies were measured at standard test conditions (STC). DSM-A was made by Dyepower Consortium and was characterized at the ESTER laboratory of the University of Rome 'Tor Vergata'. The conversion efficiency was measured under real outdoor conditions. Meanwhile DSM-B thermal and optical properties were obtained from [19]. In this case, the dye cells were supposed to be integrated in high performing glass with a very low U-value. For a more realistic study, the electrical efficiency was considered the same as DSM-A.

Table 5. Characteristics of STPV elements.

\begin{tabular}{ccccccc}
\hline Window & U-Value $\left(\mathbf{W} / \mathbf{m}^{\mathbf{2}} \mathbf{K}\right)$ & Tvis & Tsol & g-Value & $\varepsilon$ & Efficiency (\%) \\
\hline a-Si 20 & 2.783 & 0.158 & 0.120 & 0.253 & 0.525 & 3.79 \\
a-Si 40 & 2.783 & 0.324 & 0.242 & 0.367 & 0.718 & 2.53 \\
DSM-A & 3.730 & 0.330 & 0.100 & 0.200 & 0.837 & 3.00 \\
DSM-B & 0.840 & 0.200 & 0.140 & 0.150 & 0.837 & 3.00 \\
\hline
\end{tabular}

\subsection{Validation}

The IDA ICE 4.7.1 simulation program was used for this study. The STD building was built and validated using data retrieved from the literature. Olivieri et al. work was used as a reference [9].

The Olivieri et al. building is supposed to be located in Madrid and has an unshaded south-facing facade with a window to wall ratio (WWR) of $44 \%$, and the exterior wall has a U-value of $0.66 \mathrm{~W} / \mathrm{m}^{2} \mathrm{~K}$. The authors used Energy Plus to make all simulations. To validate the model used for this study, the energy performance of five STPV double glazing elements, introduced by [9], was evaluated.

Each a-Si element corresponds to a specific degree of transparency moving from 0 to 40 and the optical properties of STPV were experimentally characterized in order to obtain the spectral data necessary to carry out simulations. The thermal and optical properties of the glazing elements retrieved from [9] are listed in Table 6. The reference glass (RG) is a common double glazing system defined in the IGDB (International Glazing Database).

Table 6. Thermal and optical proprieties of the glazing elements used for validation.

\begin{tabular}{ccccccc}
\hline Glazing Element & U-Value $\left(\mathbf{W} / \mathbf{m}^{\mathbf{2}} \mathbf{K}\right)$ & Tvis & Tsol & g-Value & STC Power Density $\left(\mathbf{W} / \mathbf{m}^{\mathbf{2}}\right)$ & $\varepsilon$ \\
\hline 0 & 2.783 & 0.003 & 0.002 & 0.145 & 61.95 & 0.315 \\
10 & 2.783 & 0.101 & 0.077 & 0.216 & 44.25 & 0.45 \\
20 & 2.783 & 0.158 & 0.120 & 0.253 & 37.93 & 0.525 \\
30 & 2.783 & 0.249 & 0.186 & 0.316 & 31.6 & 0.633 \\
40 & 2.783 & 0.324 & 0.242 & 0.367 & 25.28 & 0.718 \\
RG & 2.783 & 0.461 & 0.382 & 0.473 & - & 0.83 \\
\hline
\end{tabular}


Figure 4 shows the energy consumption percentage error calculated between Olivieri et al.'s data obtained with Energy Plus and the Ester laboratory of 'Tor Vergata' data obtained with IDA ICE software (Version 4.7.1, Equa Simulation, Solna, Sweden). The left graph in the figure shows the percentage error evaluated with respect to the specific energy demand considered (heating, cooling, PV production, and lighting). In this way, a direct comparison between the capabilities of calculations of the two softwares can be evidenced. It can be noted that cooling and heating demand present small percentage errors spanning from $0.5 \%$ to approximately $3 \%$. PV production and lighting reach higher error values ranging from $3 \%$ to more than $8 \%$. In the graph on the right the same error is normalized with respect to the total energy demand evidencing the importance of each energy contribution with respect to the total energy demand. In this case the errors are negligible; however lighting always counts more with a decreasing trend as the a-Si modules' transparency decreases. Since, as the window becomes more opaque, more artificial light is required to meet the target illuminance, the reason for this higher difference could be related to the way the two softwares evaluate artificial lighting demand.

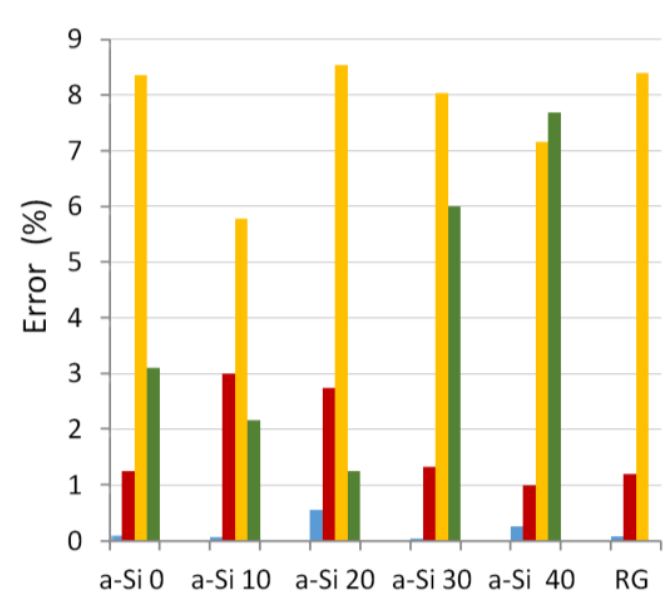

(A)

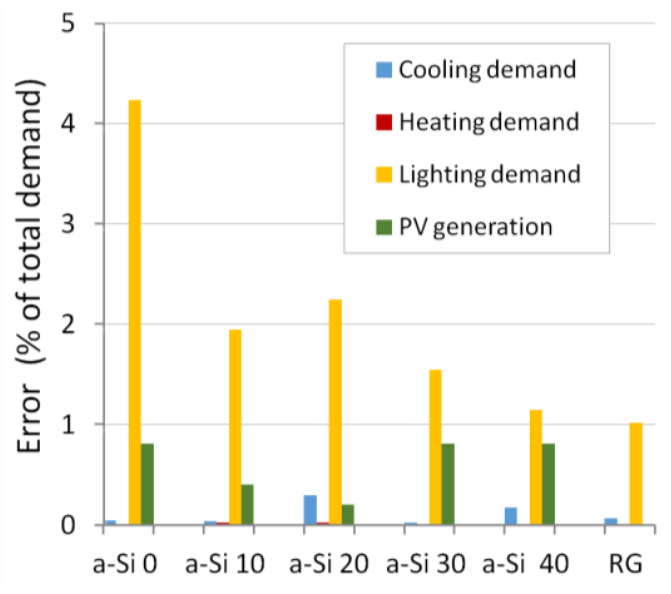

(B)

Figure 4. Simulation errors between Energy Plus and IDA ICE evaluated on the validation case of Madrid. (A) Percentage error normalized to the specific energy demand. (B) Percentage error evaluated with respect to the total building energy demand.

\section{DSM-A Thermal and Electrical Characterization}

The DSM-A provided by Dyepower consortium was tested in outdoor conditions using the Solar Test Boxes (STB). method conceived by ESTER lab [27].

The STB method uses experimental data and dynamic simulation to evaluate the thermal characteristics of transparent and semi-transparent materials in outdoor conditions. It uses two identical small boxes, a reference box and a test box (Figure 5), heavily insulated with the exception of one vertical wall equipped with a double pane glazing system (reference box) and a glass of unknown characteristics (test box).

The glazed walls are exposed outdoors toward the south for several days. The inside air temperature is measured together with the inner and outer wall temperatures of the glasses. A dynamic simulation model of the boxes, built in the IDA ICE environment, is calibrated with the experimental data of the reference box and then used with a developed methodology to retrieve the U-value and the solar heat gain coefficient of the test box glazing.

A DSM glass system, as shown in Figure 5, was tested during a monitoring campaign carried on in April 2016. The detailed description of the methods and results will be published in a future paper.

The U-value and solar heat gain were evaluated with the described method and the results are listed in Table 3. Moreover the U-value was also measured in steady state conditions indoors (Figure 6, right) using a flux meter Albhorn, mod. MA259035 and the result confirmed the value obtained with 
the dynamic method in outdoor conditions. During the outdoor campaign, the DSM was connected to an electric load so that the electrical characteristics could also be measured. From these results, the average electrical efficiency listed in Table 5 was estimated. The value obtained also confirms the results obtained in [21].



Figure 5. The two boxes used for the STB method.

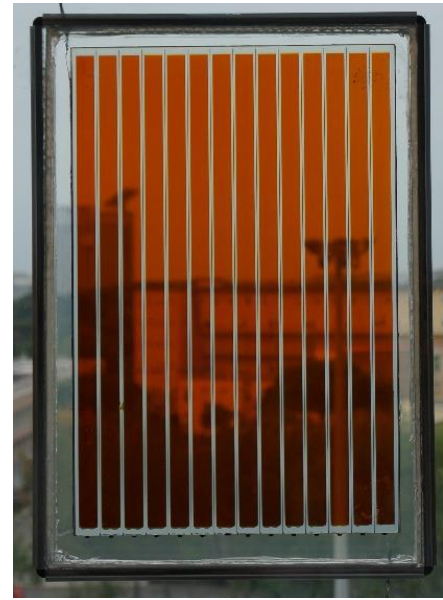

(A)

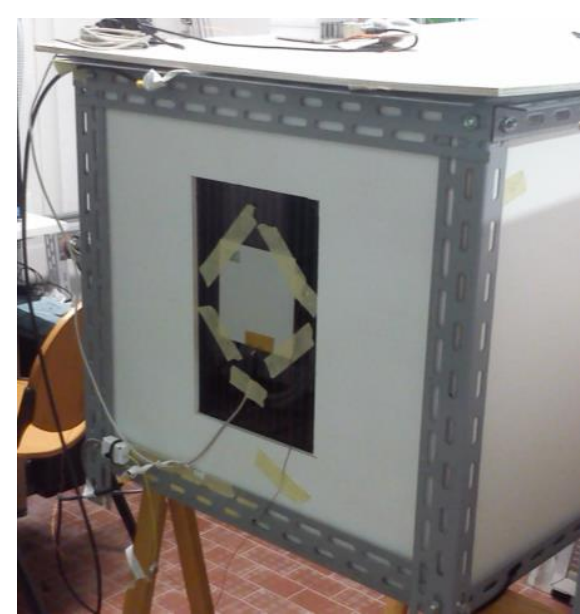

(B)

Figure 6. (A) Dye Sensitized Solar Module (DSM-A) tested; (B) the test box equipped with DSM-A during the U-value measurements with a flux meter, carried out in the indoor laboratory to validate the STB method.

\section{Results and Discussion}

The simulations were conducted for the three selected cities with various orientations and four semi-transparent photovoltaic glazing systems, compared with a reference double glazing. As reported in Section 2, the study was divided into two phases; A and B.

\subsection{Phase A}

In this phase, the total annual energy consumption in $\mathrm{kWh} / \mathrm{m}^{2}$, defined as the energy purchased to or generated within the building, which consisted of cooling, heating, lighting, and photovoltaic energy generation was analyzed for the STD office building. The main purpose was to identify the 
glazing element that presented the best performance under different conditions. Furthermore the energy balance index (EBI) was calculated as the algebraic sum of all energy contributions so that the production of photovoltaic energy is subtracted from the overall consumption.

Figure 7 shows the energy balance (A) and the EBI index (B) for the three locations considering the external wall exposed towards the north.
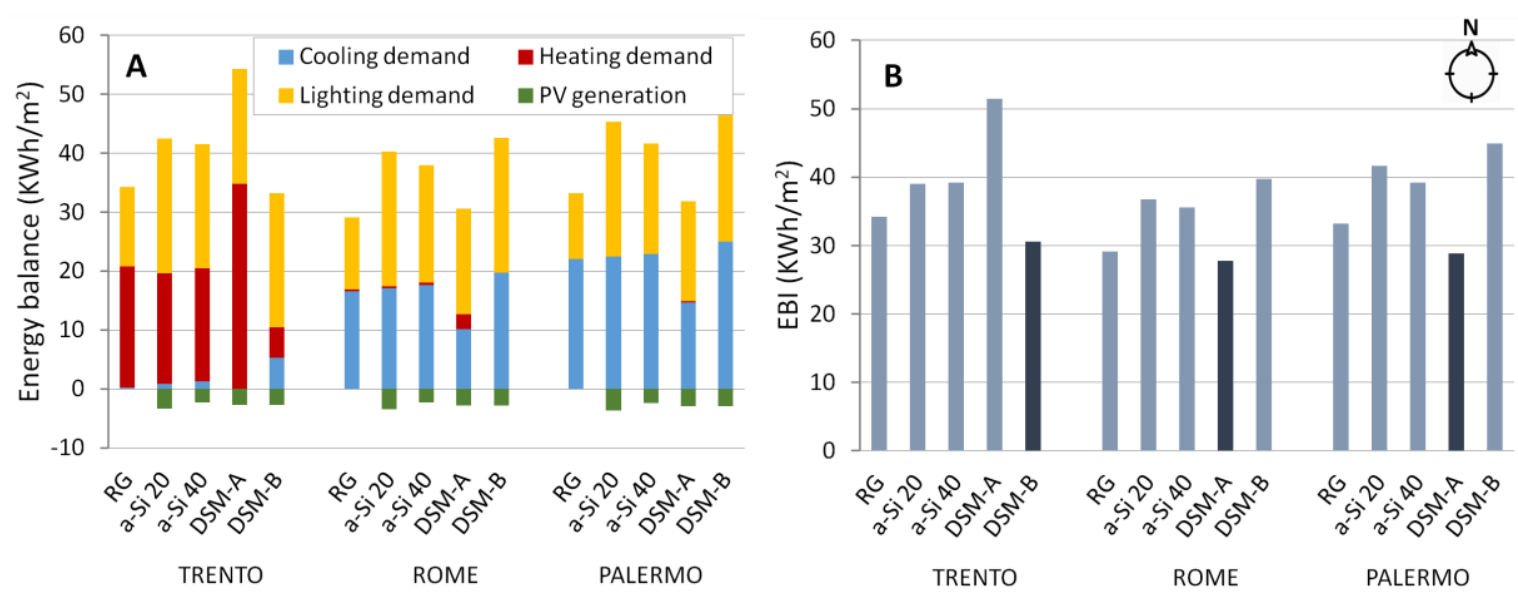

Figure 7. (A) Energy balance for the various STPV tested, compared to the reference glass (RG) of the STD building with northern exposure at the three locations; (B) Energy balance index (EBI) index evaluated for the same exposures and glazing elements.

It can be observed that the traditional double glazing RG presents different behaviors in the three cities; concerning heating and cooling, in Trento, only heating demand is present, while in Rome and Palermo, the opposite occurs. In Trento only one element, the DSM-B, is responsible for a cooling demand that cannot be considered negligible $\left(5.3 \mathrm{kWh} / \mathrm{m}^{2}\right)$.

In Trento, DSM-A has the maximum heating demand, $34.8 \mathrm{kWh} / \mathrm{m}^{2}$, while the DSM-B has the lowest cooling demand of about $5 \mathrm{kWh} / \mathrm{m}^{2}$. The maximum lighting demand occurs with the DSM-B and a-Si 20.

Rome and Palermo have similar consumption. Indeed, cooling demand is dominant in both cities, even if heating demand is not negligible for the DSM-A element in Rome. In these cities cooling demand is the highest with DSM-B glazing and the lowest with DSM-A. On the contrary, in Trento heating is dominant, and it is greatly reduced by using DSM-B glass.

Semi-transparent photovoltaic element a-Si 20 generated the highest energy; in fact it has the highest value of conversion efficiency among all the selected items.

It has to be remarked that, if northern exposure is considered, the PV production is mainly due to the diffuse component of solar irradiance.

The EBI index is shown in Figure 7B. EBI shows that the elements that have the lowest annual consumption are DSM-B for Trento and DSM-A for Rome and Palermo. The increase of heat in the south side produces an increase of cooling demand, as shown in Figure 8A, which is a maximum with RG glazing and a minimum with a-Si 20 in Trento and DSM-A in Rome and Palermo.

In Trento, DSM-A maintains the same trend as on the north side and the cooling demand remains negligible, while heating demand is predominant $\left(19.6 \mathrm{kWh} / \mathrm{m}^{2}\right)$. The a-Si 20 provides the highest energy consumption value for lighting demand. In Rome and Palermo, heating demand is negligible considering all the window types. In Trento, DSM-B has the lowest consumption, while in Rome and Palermo, DSM-A results as the best performing.

Also for EBI (Figure 8B), the same DSM had the lowest energy consumption with respect to the other elements. PV production is almost equivalent for all sites and technologies; however a slight improvement in production is visible in Trento due to the more favorable irradiance incidence on a 
vertical wall for higher latitudes where the sun elevation is lower. Considering PV production, a-Si-20 is the most well performing for all sites.
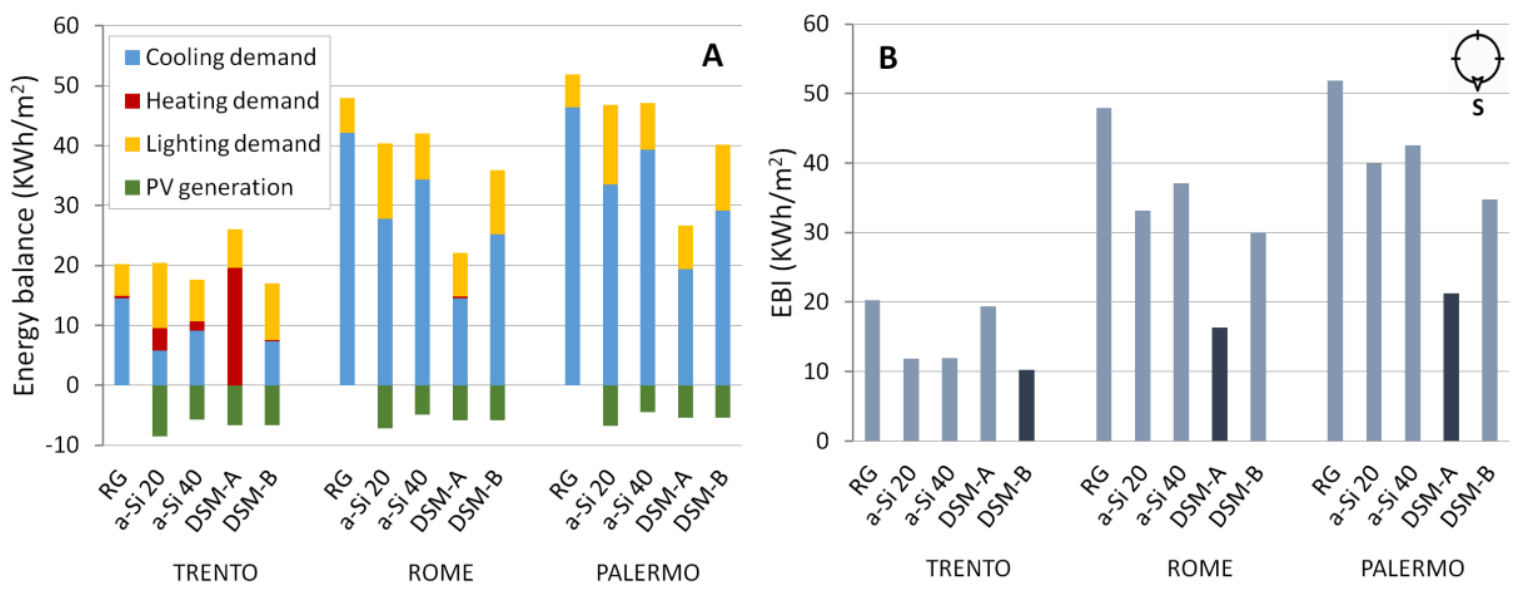

Figure 8. (A) Energy balance for the various STPV tested, compared to the reference glass (RG) of the STD building with southern exposure at the three locations; (B) EBI index evaluated for the same exposure and glazing elements.

Figure 9 presents the results for the eastern orientation. The cooling demand in Trento (Figure 9A) is similar to the situation examined earlier. In fact, the range of consumption values reported with eastern orientation is $1 \mathrm{kWh} / \mathrm{m}^{2}$ less than those of the south side. Instead heating demand is not negligible as with southern exposure. The maximum heating consumption is achieved with the DSM-A, while the minimum is reached with the DSM-B. In the other cities, the heating values are negligible, with the exception of Rome with semi-transparent DSM-A.
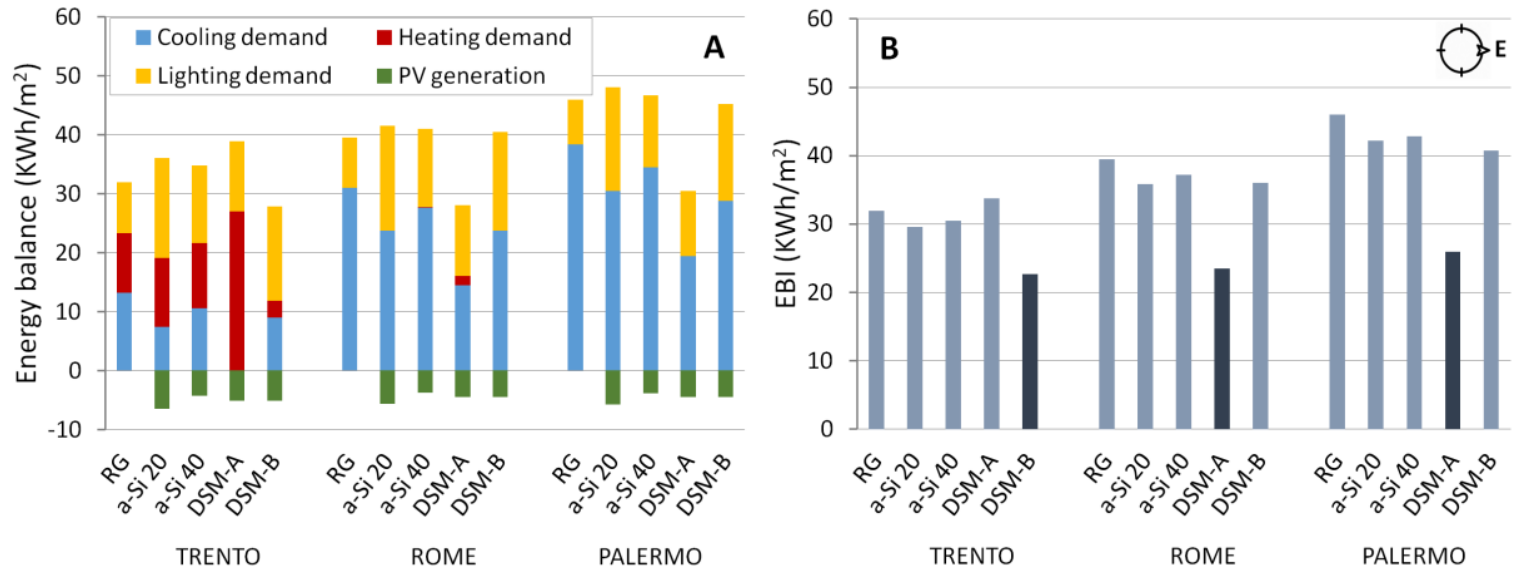

Figure 9. (A) Energy balance for the various STPV tested, compared to the reference glass (RG) of the STD building with an eastern orientation at the three locations; (B) EBI index evaluated for the same orientation and glazing elements.

On the contrary, the cooling demand for Rome and Palermo has a behavior similar to the southern side.

The energy balance index EBI shows that also in this case the best performing elements are DSM-B (Trento) and DSM-A (Rome-Palermo).

The results of the simulation on the western orientation reproduce, with different values, the trend of consumption previously described for the eastern orientation (Figure 10A). 

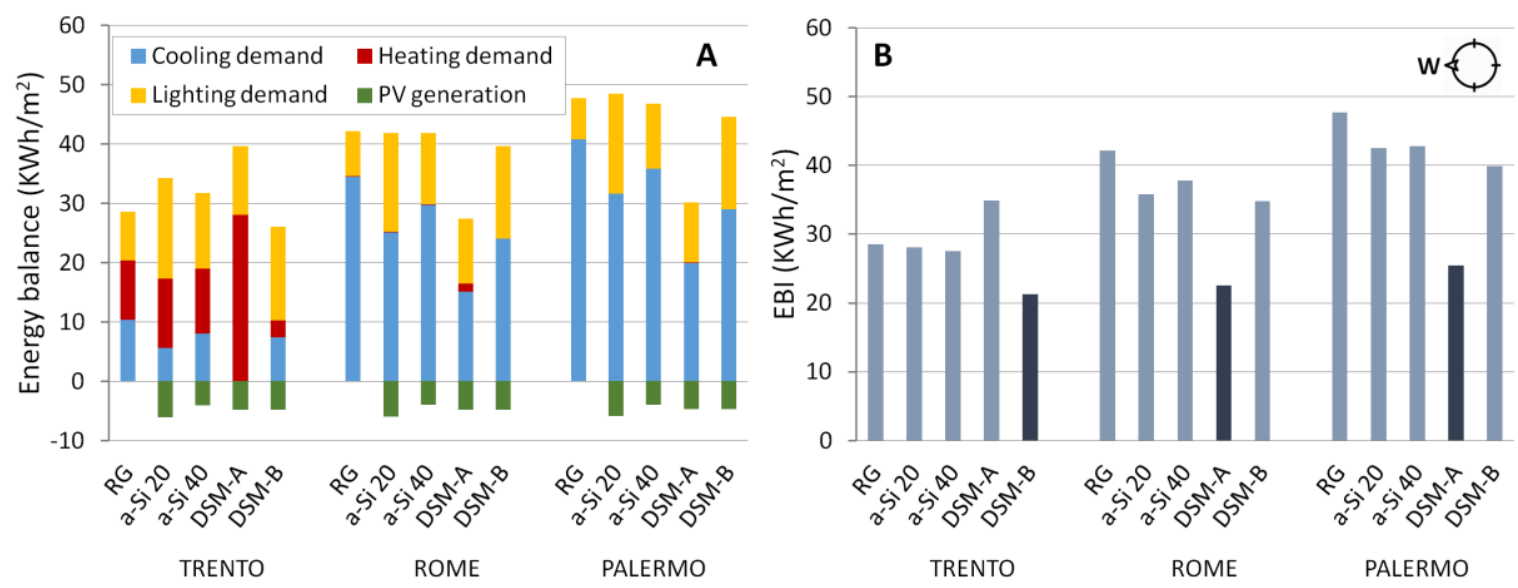

Figure 10. (A) Energy balance for the various STPV tested, compared to the reference glass (RG) of the STD building facing west at the three locations; (B) EBI index evaluated for the same orientation and glazing elements.

Nevertheless, in Rome and Palermo, the cooling demand and the production of photovoltaic energy are slightly greater, while the heating demand decreases compared to the East since the air temperature is higher in the afternoon than in the morning.

The energy balance index (see Figure 10B), shows that even for this orientation of the glazing elements, the best performance among those we studied were as follows: DSM-B for Trento and DSM-A for Rome and Palermo.

Table 7 resumes the best choices of glazing elements for the three cities and the four orientations based on the EBI evaluation. DSM-B, which presents better insulation performance, is more suitable for a cold climate while DSM-A, having minor insulation, is preferable in a warm climate.

Table 7. Best choice of glazing elements for the three locations and the four orientations studied.

\begin{tabular}{cccc}
\hline Orientation & TRENTO & ROME & PALERMO \\
\hline N & DSM-B & DSM-A & DSM-A \\
S & DSM-B & DSM-A & DSM-A \\
E & DSM-B & DSM-A & DSM-A \\
W & DSM-B & DSM-A & DSM-A \\
\hline
\end{tabular}

\subsection{Phase $B$}

In this phase, the entire floor of the building was simulated to determine the most efficient solutions in terms of energy saving under different conditions. The 30 office rooms have the same characteristics as the office model simulated in Phase A; the corridor has only the light as the internal load, with the control sensor set to $500 \mathrm{~lx}$.

Two types of reference buildings were tested; the STD with the reference glazing RG and the NZEB with the reference glazing elements listed in Table 4.

For each type of reference, STD and NZEB, the windows were then replaced by inserting the most performing elements identified in Phase A in the three cities (see Table 7). The performance of the references with respect to the most performing solution was compared for the North/South (N/S) and East/West (E/W) orientations (Figures 11 and 12).

Twenty-four simulations were conducted in total; twelve for the North/South exposure and twelve for the East/West exposure.

For the N/S orientation, as shown in Figure 11B, the NZEB building equipped with RG outperformed the STD with RG only in Palermo. This is mainly due to the fact that cooling is the greatest thermal energy demand. Indeed, for Rome and Trento, the high insulation of the walls 
and windows, required by NZEB, causes overheating of the building, which results in a high cooling demand. This is not the case in Palermo since the U-value of the reference glass in NZEB is higher than that in STD. Moreover the U-values for the walls in STD and NZEB are comparable, so the overheating is less for NZEB (see Tables 3 and 4).
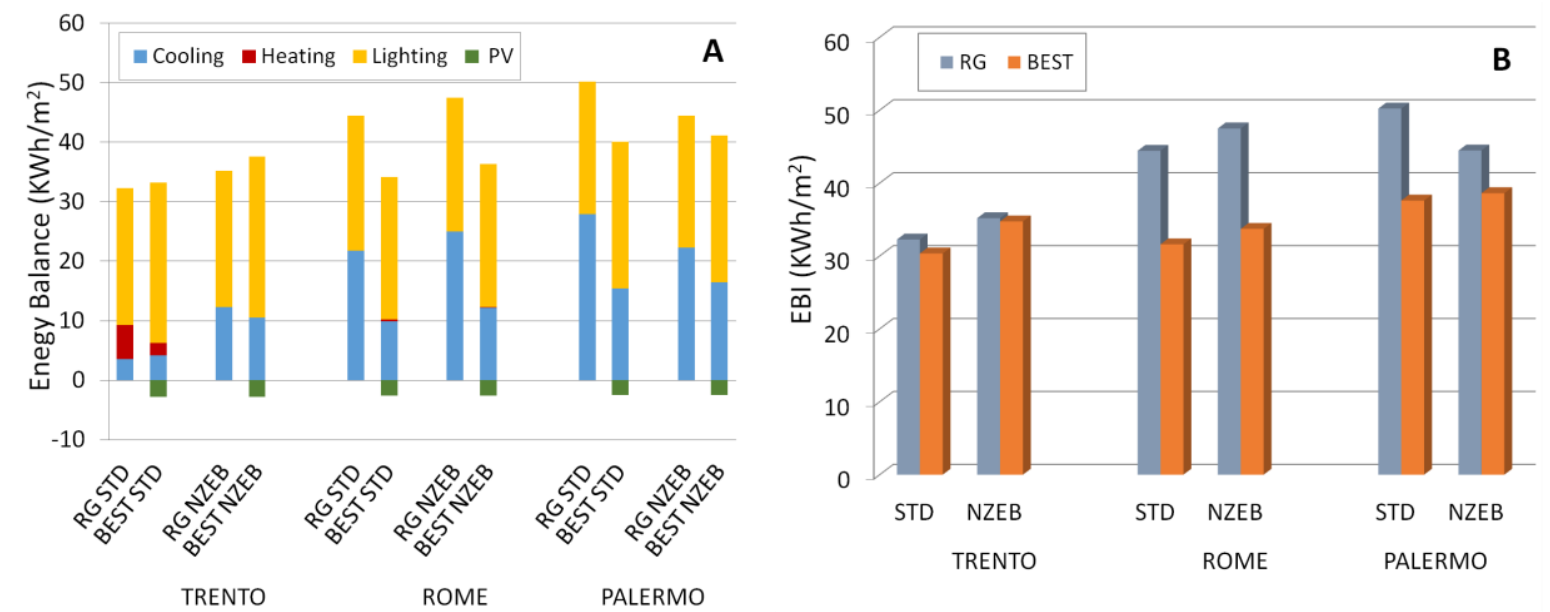

Figure 11. (A) Energy balance for the BEST solution compared to the reference glass (RG) of the STD and NZEB models at the N/S orientation of the building; (B) EBI index evaluated for the same exposure and glazing elements.


Figure 12. (A) Energy balance for the BEST solution compared to the reference glass (RG) of the STD and NZEB models on the E/W orientation of the building; (B) EBI index evaluated for the same exposure and glazing elements.

A considerable difference in energy demand is observed when DSM-A is used instead of RG in Rome and Palermo (Figure 11A). In fact, the cooling demand decreases in all the BEST simulations except in Trento, where the BEST STD cooling value is a little higher than the RG STD cooling value. Heating demand is not negligible only in Trento, and it is considerably reduced by the DSM-B BEST glass.

Concerning lighting demand, when BEST is used, the transparency decreases and the lighting demand increases because the amount of light that passes through the window decreases due to the low transparency of DSM.

The minimum EBI difference between BEST and RG is obtained in the NZEB building in Trento $(1.25 \%)$, while the maximum EBI difference is obtained in Rome, always considering the NZEB building (29\%). In Palermo, while the RG STD has a higher EBI than the RG NZEB, we observe that BEST NZEB 
consumes more energy than BEST STD. This is due to the fact that RG NZEB is less insulated than RG STD in the glazing component, while, once BEST is applied to both models, the lower wall U-value of NZEB tends to overheat the office. Under these specific conditions and hypotheses, it can be concluded that in Trento the use of STPV with a N/S orientation is not producing a convenient improvement in energy saving. On the contrary, in Rome the maximum saving is observed.

For the E/W orientation (Figure 12B), the NZEB with RG building outperforms the STD with RG, also in Trento. Indeed the E/W orientation increases both heating and cooling demand with respect to the N/S orientation in STD. This is due to the difference in sun elevation, with a lower greenhouse effect in winter and a higher effect in summer.

The maximum value of cooling demand is produced by the RG STD in Palermo, while the minimum is reached in Trento by BEST STD.

As for the N/S side, only the STD simulations for Trento show a heating demand that it is not negligible.

Lighting demand presents higher values in the BEST simulations for the same reason as in the N/S orientation.

The minimum EBI difference between RG and BEST for NZEB is observed in Trento (2.55\%), while maximum is obtained in Rome for the same building (34.65\%).

The trend of the simulations is very similar to those described in the N/S side, but the total energy balance for all the simulations in the E/W orientation (Figure 12A) presents higher values than N/S, side except for the BEST NZEB in Rome (Figure 11A).

For each series of simulations, the EBI improvement of BEST with respect to RG (for STD and NZEB models in the three cities) was calculated for the two sides, N/S and E/W, as shown in Table 8.

Table 8. Percentage differences between the EBI calculated for RG and BEST, in the cases of the STD and NZEB models at the three locations.

\begin{tabular}{ccccccc}
\hline \multirow{2}{*}{ Orientation } & \multicolumn{2}{c}{ TRENTO } & \multicolumn{2}{c}{ ROME } & \multicolumn{2}{c}{ PALERMO } \\
\cline { 2 - 6 } & STD (\%) & NZEB (\%) & STD (\%) & NZEB (\%) & STD (\%) & NZEB (\%) \\
\hline N/S & 5.92 & 1.25 & 28.9 & 29.0 & 25.1 & 13.2 \\
E/W & 10.6 & 2.55 & 25.8 & 34.7 & 26.7 & 15.4 \\
\hline
\end{tabular}

The difference between the $\mathrm{E} / \mathrm{W}$ and N/S percentages evidences the saving obtained by one orientation or the other. It can be observed that for almost all locations this difference is positive, indicating that an $\mathrm{E} / \mathrm{W}$ orientation is more favorable. This is because north exposure is less effective in $\mathrm{PV}$ production than all the other orientations.

\section{Conclusions}

A study has been carried out to explore the annual energy saving potential of STPV integrated into glazing systems of an office building. A reference office building used by IEA Tasks 25, 27, and 31 has been built in a dynamic simulation environment, and the model has been validated through data coming from the literature. Four STPVs have been tested as glazing elements and their performance has been compared to a reference glass at three different locations in Italy, with varying orientations of the office building. Dye sensitized solar modules resulted as the best performing devices for all orientations and climate zones. The best configurations obtained by the previous analysis have been tested on two reference office buildings, STD and NZEB, simulating an entire floor exposed at the North/South and East/West orientations at the three locations. STD has the average characteristics of an existing building in Italy, similar to what is prescribed by Italian regulations of 2006. NZEB has the characteristics of Nearly Zero Energy Buildings' minimum requirements, as in the more recent 2015 Italian norm. Heating demand was almost negligible for the two orientations and at all locations so that the major contribution of thermal energy is cooling. Surprisingly the study, under the hypothesis 
considered, evidenced that the NZEB building equipped with the reference glass prescribed by the norm consumed more energy than the STD building in Rome, with an EBI increment of 7\%, and also in Trento, with an EBI increment of 9\% due to overheating during summer if the building is positioned in the N/S orientation. Only Rome experiences overheating for the E/W orientation, with an EBI increment of $4 \%$. This result seems to lead to the conclusion that the requirements in the perspective of NZEB could have been considered too stringent for insulation properties, especially for the climate zone of Rome. Moreover the benefit of introducing the BEST solution in the NZEB model reduces the overheating effect, improving the saving potential with respect to RG, especially for the E/W orientation (EBI improvement of 34.7\%). Even with these considerations in mind, Rome and Palermo benefit from the use of semi-transparent PV in the glazing elements, resulting in an average EBI improvement of around $32 \%$ and $14 \%$, respectively, for the NZEB building at both orientations. On the contrary, Trento shows an improvement of only $1.25 \%$ and $2.55 \%$ for the N/S and E/W orientations of the NZEB building, respectively, and these percentages grow to approximately $6 \%$ and $11 \%$ if the BEST solution is implemented in STD.

Author Contributions: Cristina Cornaro conceived the topic of the paper and designed the method together with Giulia Basciano; Giulia Basciano performed the simulations and data analysis with the support of Valerio Adoo Puggioni and Marco Pierro; all the authors contributed to the analysis and discussion of results; Cristina Cornaro and Giulia Basciano wrote the paper.

Conflicts of Interest: The authors declare no conflict of interest.

\section{Nomenclature}

$\begin{array}{ll}\text { Acronyms } & \\ \text { a-Si } 20 & \text { Amorphous silicon-20\% transparency } \\ \text { a-Si } 40 & \text { Amorphous silicon-40\% transparency } \\ \text { BEST } & \text { Best solution for all orientations obtained in Phase A } \\ \text { DSC } & \text { Dye Sensitized Cell } \\ \text { DSM-A } & \text { Dye Sensitized Module-Type A } \\ \text { DSM-B } & \text { Dye Sensitized Module-Type B } \\ \text { EBI } & \text { Energy Balance Index } \\ \text { IGDB } & \text { International Glazing Database } \\ \mathrm{N}, \mathrm{S}, \mathrm{E}, \mathrm{W} & \text { North, South, East, West } \\ \mathrm{NZEB} & \text { Nearly Zero Energy Building } \\ \text { RG } & \text { Reference Glass } \\ \text { STB } & \text { Solar Test Boxes } \\ \text { STD } & \text { Standard } \\ \text { STPV } & \text { Semi-Transparent Photovoltaic } \\ \text { WWR } & \text { Window to Wall Ratio } \\ \text { Variables } & \\ \eta & \text { Electrical Efficiency of PV modules, } \% \\ \varepsilon & \text { Emissivity, dimensionless } \\ \text { COP } & \text { Coefficient of performance, dimensionless } \\ \mathrm{g} & \text { Solar heat gain, dimensionless } \\ \text { Tsol } & \text { Solar Transmittance, dimensionless } \\ \text { Tvis } & \text { Visible transmittance, dimensionless } \\ \mathrm{T}_{\text {avg }} & \text { Annual average temperature, }{ }^{\circ} \mathrm{C} \\ \mathrm{T}_{\text {max }} & \text { Annual maximum temperature, }{ }^{\circ} \mathrm{C} \\ \mathrm{T}_{\text {min }} & \text { Minimum annual temperature, } \\ \mathrm{U} & \text { Thermal transmittance, } \mathrm{C} / \mathrm{m}^{2} \mathrm{~K} \\ & \end{array}$

\section{References}

1. European Union. Directive 2002/91/EC of the European Parliament and of the Council of December 16th, 2002 on the Energy Performance of Buildings; European Union: Brussels, Belgium, 2003. 
2. European Union. Directive 2010/31/EU of the European Parliament and of the Council of May 19th, 2010 on the Energy Performance of Buildings (Recast); European Union: Brussels, Belgium, 2010.

3. Italian Norm. Interministerial Decret 26 June 2015-Application of Calculation Methodologies for Energy Performance and Definition of Prescription for Minimum Requirements of Buildings; Italian Government: Rome, Italy, 2015.

4. Skandalos, N.; Karamanis, D. PV glazing technologies. Renew. Sustain. Energy Rev. 2015, 49, $306-322$. [CrossRef]

5. Cuce, E.; Riffat, S.B. A state-of-the-art review on innovative glazing technologies. Renew. Sustain. Energy Rev. 2015, 41, 695-714. [CrossRef]

6. Saifullah, M.; Gwak, J.; Yun, J.H. Comprehensive review on material requirements, present status, and future prospects for building-integrated semitransparent photovoltaics (BISTPV). J. Mater. Chem. A 2016, 4, 8512-8540. [CrossRef]

7. Chae, Y.T.; Kim, J.; Park, H.; Shin, B. Building energy performance evaluation of building integrated photovoltaic (BIPV) window with semi-transparent solar cells. Appl. Energy 2014, 129, 217-227. [CrossRef]

8. Olivieri, L.; Caamãno-Martin, E.F.; Olivieri, F.; Neila, J. Integral energy performance characterization of semi-transparent photovoltaic elements for building integration under real operation conditions. Energy Build. 2014, 68, 280-291. [CrossRef]

9. Olivieri, L.; Caama no-Martín, E.F.; Moralejo-Vazquez, F.J.; Martín-Chivelet, N.; Olivieri, F.; Neila-Gonzalez, F.J. Energy saving potential of semi-transparent photovoltaic elements for building integration. Energy 2014, 76, 572-583. [CrossRef]

10. Liao, W.; Xu, S. Energy performance comparison among see-through amorphous silicon PV (photovoltaic) glazings and traditional glazings under different architectural conditions in China. Energy 2015, 83, 267-275. [CrossRef]

11. Fakharuddin, A.; Jose, R.; Brown, T.M.; Fabregat-Santiago, F.; Bisquert, J. A perspective on the production of dye-sensitized solar modules. Energy Environ. Sci. 2014, 7, 3952-3981. [CrossRef]

12. Cornaro, C.; Di Carlo, A. Organic Photovoltaics for Energy Efficiency in Building. In Nano and Biotech Based Materials for Energy Building Efficiency; Torgal, F.P., Buratti, C., Kalaiselvam, S., Granqvist, C.-G., Ivanov, V., Eds.; Springer: Cham, Switzerland, 2016; pp. 321-355.

13. D’Ercole, D.; Dominici, L.; Brown, T.M.; Michelotti, F.; Reale, A.; Di Carlo, A. Angular response od dye solar cells to solar and spectrally resolved light. Appl. Phys. Lett. 2011, 99. [CrossRef]

14. Tian, T.; Yu, X.; Zhang, J.; Duan, W.; Tian, F.; Yu, T. The influence of environmental factors on DSSCs for BIPV. Int. J. Elettrochem. Sci. 2012, 7, 4686-4691.

15. Kang, J.G.; Kim, J.H.; Kim, J.T. Performance evaluation of DSC windows for buildings. Int. J. Photoenergy 2013. [CrossRef]

16. Kang, J.G.; Kim, J.H.; Jang, H.B.; Kim, J.T. Characteristics of DSSC panels with silicone encapsulant. Int. J. Photoenergy 2015. [CrossRef]

17. Mastroianni, S.; Lanuti, A.; Penna, S.; Reale, A.; Brown, T.; Di Carlo, A.; Decker, F. Physical and Electrochemical Analysis of an Indoor-Outdoor Ageing Test of Large-Area Dye Solar Cell Devices. Chemphyschem 2012, 13, 2925-2936. [CrossRef] [PubMed]

18. Yoon, S.; Tak, S.; Kim, J.; Jun, Y.; Kang, K.; Park, J. Application of transparent dye- sensitized solar cells to building integrated photovoltaic systems. Build. Environ. 2011, 46, 1899-1904. [CrossRef]

19. Lee, J.W.; Park, J.; Jung, H.J. A feasibility study on a building's window system based on dye-sensitized solar cells. Energy Build. 2014, 81, 38-47. [CrossRef]

20. Reale, A.; Malatesta, A.; De Marco, R.; Brown, T.M.; Di Carlo, A. Estimation of Energy Production of Dye-Sensitized Solar Cell Modules for Building-Integrated Photovoltaic Applications. Energy Technol. 2014, 2, 531-541. [CrossRef]

21. Cornaro, C.; Bartocci, S.; Musella, D.; Strati, C.; Lanuti, A.; Mastroianni, S.; Penna, S.; Guidobaldi, A.; Giordano, F.; Petrolati, E.; et al. Comparative analysis of the outdoor performance of a dye solar cell mini-panel for building integrated photovoltaics applications. Prog. Photovolt. 2015, 23, 215-225. [CrossRef]

22. Björsell, N.; Bring, A.; Eriksson, L.; Grozman, P.; Lindgren, M.; Sahlin, P.; Sha-povalov, A.; Vuolle, M. IDA Indoor climate and energy. In Proceedings of the Building Simulation Conference, Kyoto, Japan, 13-15 September 1999. 
23. Italian Norm. Decret 19 August 2005, n. 192: "Fulfillment of 2002/91/CE Directive on the Energy Efficiency in Buildings"; Italian Government: Rome, Italy, 2005.

24. Rubel, F.; Kottek, M. Comments on: The thermal zones of the Earth by Wladimir Köppen (1884). Meteorol. Z. 2011, 20, 361-365.

25. Nielsen, T.R.; Rosenfeld, J.L.J.; Svendsen, S. A Simple Energy Rating for Solar Shading Devices; Technical Report; BYG DTU SR 03-02: Copenhagen, Denmark, 2003.

26. EN12464-1:2011 Light and Lighting-Lighting of Workplaces. Part 1: Indoor Work Places; European Committee for Standardization: Brussels, Belgium, 2011.

27. Cornaro, C.; Bucci, F.; Pierro, M.; Bonadonna, M.E.; Siniscalco, G. A new method for the thermal characterization of transparent and semi-transparent materials using outdoor measurements and dynamic simulation. Energy Build. 2015, 104, 57-64. [CrossRef]

(C) 2017 by the authors; licensee MDPI, Basel, Switzerland. This article is an open access article distributed under the terms and conditions of the Creative Commons Attribution (CC BY) license (http://creativecommons.org/licenses/by/4.0/). 